\title{
Radiation Shielding Properties of Spark Plasma Sintered Boron Carbide-Aluminium Composites
}

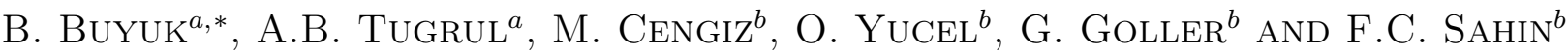 \\ ${ }^{a}$ Istanbul Technical University, Energy Institute, Nuclear Researches Division, Istanbul, Turkey \\ ${ }^{b}$ Istanbul Technical University, Metallurgical and Materials Engineering Department, Istanbul, Turkey \\ In this study gamma and neutron attenuation properties of boron carbide-aluminium $\left(\mathrm{B}_{4} \mathrm{C}-\mathrm{Al}\right)$ composites \\ were investigated. $\mathrm{B}_{4} \mathrm{C}-\mathrm{Al}$ composites were produced by spark plasma sintering method. Aluminum percentages \\ in the $\mathrm{B}_{4} \mathrm{C}-\mathrm{Al}$ composites were $0 \%, 10 \%, 15 \%$, and $20 \%$ by volume. The composite materials were performed \\ against gamma and neutron sources. Cs-137 and Co-60 gamma radioisotopes were used as gamma sources and \\ $\mathrm{Pu}-\mathrm{Be}$ neutron howitzer was used for neutron source. Theoretical mass attenuation coefficients were determined by \\ using XCOM computer code and compared with the experimental results. It has been seen that the experimental \\ results were close to the theoretical results. Total macroscopic cross-sections of the samples were determined for \\ $\mathrm{Pu}-\mathrm{Be}$ neutrons. It is concluded that increasing aluminum ratio in the $\mathrm{B}_{4} \mathrm{C}-\mathrm{Al}$ composites causes higher gamma \\ attenuation behavior for Cs- 137 and $\mathrm{Co}-60$ gamma sources and the total macroscopic cross-sections of the $\mathrm{B}_{4} \mathrm{C}-\mathrm{Al}$ \\ composites decrease by increasing $\mathrm{Al}$ concentration.
}

DOI: 10.12693/APhysPolA.128.B-132

PACS: 25.20.Dc, 81.05.Je

\section{Introduction}

Boron carbide is one the most important materials for nuclear applications thanks to its good thermal neutron capture capability [1]. Some additives including aluminium are used to increase densification properties of boron carbide $[2,3]$. The radiation shielding properties of some boron carbide based composites were figured out in the literature. Buyuk et al. reported that the gamma attenuation properties of the boron carbidetitanium diboride composites were increased when the average boron carbide particle size was decreased in the composites [4]. In addition reinforcing titanium diboride causes higher gamma attenuation properties of boron carbide-silicon carbide composites [5]. Furthermore, it has been reported that increasing silicon carbide ratio in boron carbide-silicon carbide composites increases the gamma shielding even though thermal neutron shielding decreases [6].

In this study, boron carbide-aluminium $\left(\mathrm{B}_{4} \mathrm{C}-\mathrm{Al}\right)$ composites were studied against gamma and neutron sources. The radiation shielding properties of the samples were carried out. Finally, the effect of aluminium ratio on the radiation shielding properties of the composites were investigated and evaluated.

\section{Experimental procedure}

Boron carbide-aluminium composites were produced by spark plasma sintering technique. The composites have different aluminium ratios $(0 \%, 10 \%, 15 \%$, and $20 \%)$

*corresponding author; e-mail: buyukbu@itu.edu.tr by volume. Materials were sintered at $1450{ }^{\circ} \mathrm{C}$ for $4 \mathrm{~min}$ where the densities of the $2.469,2.484,2.494$, and $2.513 \mathrm{~g} / \mathrm{cm}^{3}$, respectively.

Gamma and neutron transmission techniques were used in the experiments which were based on detection of incoming radiation from the source. The radiation source and radiation detector were put on the same axis. The radiation intensity is measured with/without the material then results were evaluated and interpreted [1]. The schematic view of the gamma and neutron transmission techniques was given in Fig. 1.

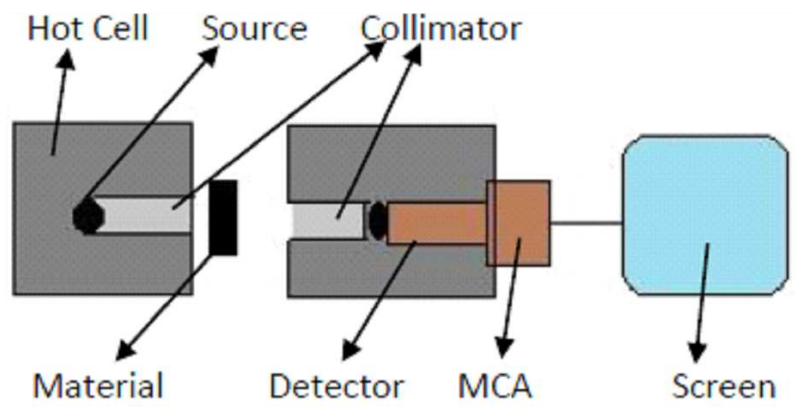

Fig. 1. Schematic view of gamma and neutron transmission techniques.

Cs-137 and Co-60 gamma radioisotopes were used for gamma radiation. Cs-137 gamma source has a single gamma energy peak at $0.662 \mathrm{MeV}$ where Co-60 has two peaks at 1.17 and $1.33 \mathrm{MeV}$ (mean energy $1.25 \mathrm{MeV}$ ). Cs-137 has 30.2 years half life and $8.59 \mathrm{MCi}$ activity where Co-60 has 5.27 years half life and $8.23 \mathrm{MCi}$ activity [1]. Canberra Model (802-2X2) NaI Scintillation detector $(5.5 \mathrm{~cm}$ diameter) was placed $15 \mathrm{~cm}$ far from the source. digiBASE model PMT base with integrated 
bias supply, preamplifier and digital multichannel analyser which was supplied with MAESTRO-32 MCA Emulation software, was used to count gamma radiation. Both the detector and source were put in the lead houses (5 cm thick) which have $7 \mathrm{~mm}$ hole collimator on the same axis. The accumulation time was adjusted as $600 \mathrm{~s}$.

$\mathrm{A} \mathrm{Pu}-\mathrm{Be}$ neutron howitzer (NH-3) was used for neutron source. $\mathrm{Pu}-\mathrm{Be}$ neutron source has $5 \mathrm{Ci}$ activity, $10^{6} \mathrm{n} /\left(\mathrm{cm}^{2} \mathrm{~s}\right)$ neutron flux and $5 \mathrm{MeV}$ average neutron energy [6]. Paraffin wax (4 cm thick) was used for slowing down neutron energies to increase interaction neutrons with materials atoms [7, 8]. PM1401K model He-3 detector was used for neutron counting. A hand held computer was used to remote control of the detector. The distance between detector and souce was $40 \mathrm{~cm}$. Detector was put in a house which is combined system of boric acid ( $5 \mathrm{~cm}$ thick), paraffin wax $(8 \mathrm{~cm}$ thick) and cadmium plate $(0.1 \mathrm{~cm}$ thick). The house has a hole in $1.5 \mathrm{~cm}$ diameter to get narrow beam of neutrons. The accumulation time was $240 \mathrm{~s}$ for the neutrons.

First of all initial radiation intensity $\left(I_{0}\right)$ was measured. Finally, for each material, the gamma and neutron counts $(I)$ were detected at different material thicknesses. To get rational evaluation, relative counts $\left(I / I_{0}\right)$ were calculated and evaluated.

\section{Results and discussion}

The relative count values were carried out for different thicknesses of the boron carbide-aluminium composites and the results were given in as relative count-material thickness graphs in Fig. 2.

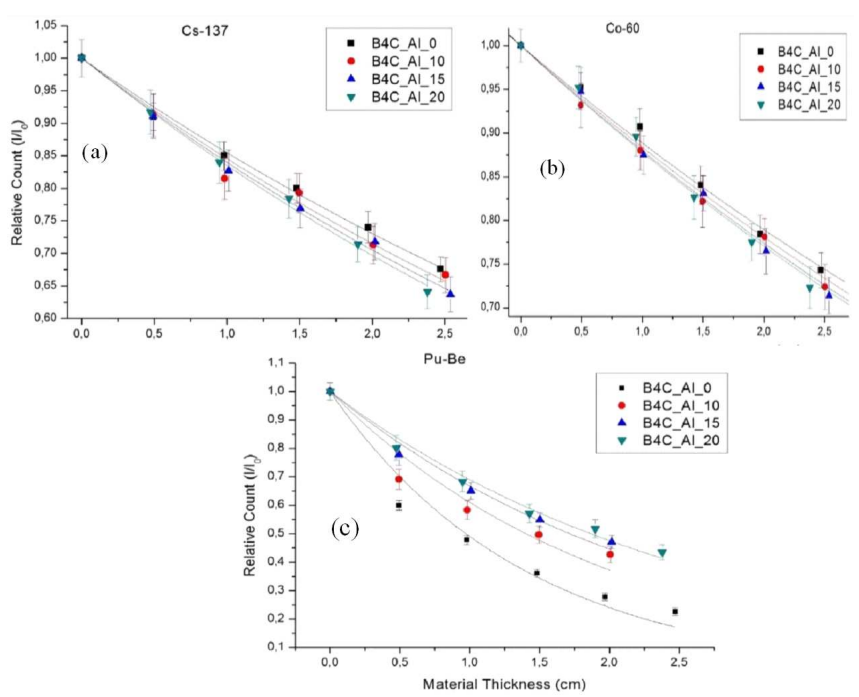

Fig. 2. Attenuation graphs of $\mathrm{B}_{4} \mathrm{C}-\mathrm{Al}$ composites for Cs-137 (a), Co-60 (b), and $\mathrm{Pu}-\mathrm{Be}$ (c) sources.

The gamma and neutron attenuation graphs were fitted exponentially according to Beer-Lambert's law as $I=I_{0} \mathrm{e}^{-\mu\left(\Sigma_{\mathrm{t}}\right) x}$ where $I_{0}$ and $I$ are incoming and passed radiation intensities, respectively. $x$ is the material thickness, $\mu$ is linear attenuation coefficient of the sample at specific gamma energy and $\Sigma_{\mathrm{t}}$ is the total macroscopic cross-section of the sample for thermal neutrons. Linear attenuation coefficients and total macroscopic crosssections were figured out by using Origin 8 program and given in Table I.

TABLE I

Linear attenuation coefficients and total macroscopic cross-sections of the materials.

\begin{tabular}{c|c|c|c|c|c|c}
\hline \hline \multirow{2}{*}{$\begin{array}{c}\text { Material } \\
\end{array}$} & \multicolumn{3}{|c|}{$\begin{array}{c}\text { Linear attenuation coefficients } \mu \\
{\left[\mathrm{cm}^{-1}\right]}\end{array}$} & $\begin{array}{c}\text { Total macroscopic } \\
\text { cross-sections } \Sigma_{\mathrm{t}} \\
{\left[\mathrm{cm}^{-1}\right]}\end{array}$ \\
\cline { 2 - 7 } & Cs-137 & Std. dev. & Co-60 & Std. dev. & Pu-Be & Std. dev. \\
\hline $\mathrm{B}_{4} \mathrm{C}-\mathrm{Al}+0$ & 0.157 & 0.003 & 0.118 & 0.003 & 0.712 & 0.054 \\
$\mathrm{~B}_{4} \mathrm{C}-\mathrm{Al} 110$ & 0.168 & 0.005 & 0.128 & 0.001 & 0.494 & 0.045 \\
$\mathrm{~B}_{4} \mathrm{C}-\mathrm{Al} 15$ & 0.174 & 0.003 & 0.130 & 0.001 & 0.404 & 0.018 \\
$\mathrm{~B}_{4} \mathrm{C}-\mathrm{Al} 20$ & 0.180 & 0.003 & 0.132 & 0.002 & 0.371 & 0.014
\end{tabular}

Mass attenuation coefficients were calculated for Cs137 and Co-60 gamma sources. On the other hand, theoretical mass attenuation coefficients were carried out by using XCOM computer code [9] and compared with the experimental results. Theoretical and experimental mass attenuation coefficients and the difference percentages were given in Table II.

TABLE II

The mass attenuation coefficients of the boron carbidealuminum composites.

\begin{tabular}{c|c|c|c|c|c|c}
\hline \hline \multirow{2}{*}{ Materials } & \multicolumn{5}{|c}{ Mass attenuation coefficients $\mu_{\mathrm{m}}\left[\mathrm{cm}^{2} / \mathrm{g}\right]$} \\
\cline { 2 - 7 } & Cs-137 & XCOM & Diff. & Co-60 & XCOM & Diff. \\
\hline $\mathrm{B}_{4} \mathrm{C}-\mathrm{Al} \_0$ & 6.359 & 7.261 & 12.42 & 4.779 & 5.357 & 10.78 \\
$\mathrm{~B}_{4} \mathrm{C}-\mathrm{Al}+10$ & 6.763 & 7.278 & 7.07 & 5.153 & 5.370 & 4.04 \\
$\mathrm{~B}_{4} \mathrm{C}-\mathrm{Al} 115$ & 6.977 & 7.287 & 4.26 & 5.213 & 5.376 & 3.04 \\
$\mathrm{~B}_{4} \mathrm{C}-\mathrm{Al} \_20$ & 7.163 & 7.295 & 1.81 & 5.253 & 5.383 & 2.42
\end{tabular}

Half value layer (HVL) is the minimum material thickness to reduce incoming radiation to its half and shows the material's radiation shielding property. Therefore HVLs were calculated for the materials and given in Table III.

TABLE III

Half value layers of the boron carbide-aluminum composites.

\begin{tabular}{c|c|c|c|c|c|c}
\hline \hline \multirow{2}{*}{ Material } & \multicolumn{5}{|c}{ Half value layers (HVL) [cm] } \\
\cline { 2 - 7 } & Cs-137 & Std. Dev. & Co-60 & Std. Dev. & Pu-Be & Std. Dev. \\
\hline B $_{4}$ C-Al_0 & 4.415 & 0.084 & 5.874 & 0.090 & 0.974 & 0.074 \\
$\mathrm{~B}_{4} \mathrm{C}-\mathrm{Al} \_10$ & 4.126 & 0.147 & 5.415 & 0.097 & 1.403 & 0.128 \\
$\mathrm{~B}_{4} \mathrm{C}-\mathrm{Al} 115$ & 3.984 & 0.069 & 5.332 & 0.041 & 1.716 & 0.076 \\
$\mathrm{~B}_{4} \mathrm{C}-\mathrm{Al}=20$ & 3.851 & 0.064 & 5.251 & 0.089 & 1.868 & 0.071
\end{tabular}

The linear attenuation coefficients were increased with raising $\mathrm{Al}$ ratio in the boron carbide-aluminium 
composites whereas total macroscopic cross-sections were decreased (Table III). In addition, from Table II, it could be seen that the difference percentages between theoretical and experimental mass attenuation coefficients were decreased with increase of aluminium ratio in the composites. So, increasing aluminium ratio causes less porous composites and close to ideal material composition. Finally, from Table III it could be said that increasing aluminium ratio increases gamma attenuation capability but decreases the thermal neutron shielding property for the boron carbide-aluminium composites.

\section{Conclusion}

Spark plasma sintered boron carbide composites were fabricated by adding $0,10,15,20 \% \mathrm{Al}$ in volume and investigated against Cs-137 and Co-60 gamma radioisotopes and $\mathrm{Pu}-\mathrm{Be}$ neutron source. Gamma and thermal neutron shielding properties of the samples were measured. The results were compatible with the theoretical values and the results in the literature. Increasing aluminium ratio in the composites brings about the higher gamma shielding property whereas provides lower thermal neutron shielding capability.

\section{Acknowledgments}

We express our gratitude to TUBITAK for financially supporting our project team by 213M163 coded project.

\section{References}

[1] G.F. Knoll, Radiation Detection and Measurement, University of Michigan, Wiley, 2002.

[2] F. Thevnot, J. Europ. Ceram. Soc. 6, 205 (1990).

[3] M. Cengiz, B. Yavas, Y. Celik, G. Goller, O. Yucel, F.C. Sahin, Acta Phys. Pol. A 125, 260 (2014).

[4] B. Buyuk, A.B. Tugrul, A.C. Akarsu, A.O. Addemir, J. Nano-Electron. Phys. 4, 1-01010 (2012).

[5] B. Buyuk, A.B. Tugrul, Radiat. Phys. Chem. 97, 354 (2014).

[6] B. Buyuk, A.B. Tugrul, Ann. Nucl. En. 71, 46 (2014).

[7] M.H. Farr, M.Sc. Thesis, Drake University, USA 1966.

[8] A.A. Gordous, Archaeometry 10, 78 (1967).

[9] M.J. Berger, J.H. Hubbell, S.M. Seltzer, J. Chang, J.S. Coursey, R. Sukumar, D.S. Zucker, K. Olsen, XCOM: Photon cross sections database, 1998. (http://www.nist.gov/pml/data/xcom/). 